\title{
An attempt to demonstrate a transmissible agent from sarcoid material*
}

\author{
D. N. MitCheLL \\ M.R.C. Tuberculosis and Chest Diseases Unit, \\ Brompton Hospital, London, S.W.3
}

\section{Summary}

The results of a controlled experiment in which an attempt was made to transmit sarcoidosis by inoculation of sarcoid and non-sarcoid lymph node homogenates into the footpads of normal and immunologically deficient mice, are reported.

The early and late changes in the footpads were assessed microscopically. A substantial proportion of the footpads of mice receiving sarcoid homogenate showed the histological characteristics typical of sarcoidosis in man and evolved fully only after a period of 6-8 months following inoculation. Moreover, positive Kveim tests were confined to a proportion of those mice given sarcoid homogenates and were all associated with a sarcoid granuloma in the footpad.

Conversely, the inflammatory lesions seen in the early histology of the footpads of mice inoculated with non-sarcoid homogenate were no longer apparent in the late histology and Kreim tests in all mice given non-sarcoid homogenate were negative.

\section{Introduction}

The cause of sarcoidosis is still unknown. Although there have been many claims implicating bacteria, viruses, fungi, protozoa or plant and chemical substances, none of these have been substantiated. Moreover, because the general histological picture of sarcoidosis is that of a non-caseating epithelioid cell granuloma and because a wide variety of microorganisms or their degradation products or chemical substances can, in man and animals, produce such granulomata, experimental animals have been used to demonstrate these features without unfortunately proving their connection with the disease in man. There is also good evidence that patients with sarcoidosis have some immunological defect, particularly of their delayed hypersensitivity response. Therefore, because no specific etiological agent has been demonstrated, it has been suggested that

* This paper has already appeared in the Lancet, (1969, ii, 81. D.N. Mitchell \& R.J.W. Rees. A transmissible agent from sarcoid tissue) and is reproduced by kind permission of the Editor.

\author{
R. J. W. REES \\ The National Institute for Medical Research, \\ Mill Hill
}

sarcoidosis represents an abnormal response of the host to non-specific agents or antigens. Against this background we report here our attempts to transmit sarcoidosis to mice by inoculating homogenates of human sarcoid tissue using both normal and immunologically deficient animals (following thymectomy and whole body irradiation).

\section{Methods and materials}

Lymph nodes were obtained by mediastinoscopy (Carlens, 1959) from three Kveim-positive patients with recent sarcoidosis; each showed typical microscopic changes (Fig. 1). As a control, a lymph node was obtained from the groin at operation for ligation of varicose veins in an otherwise apparently

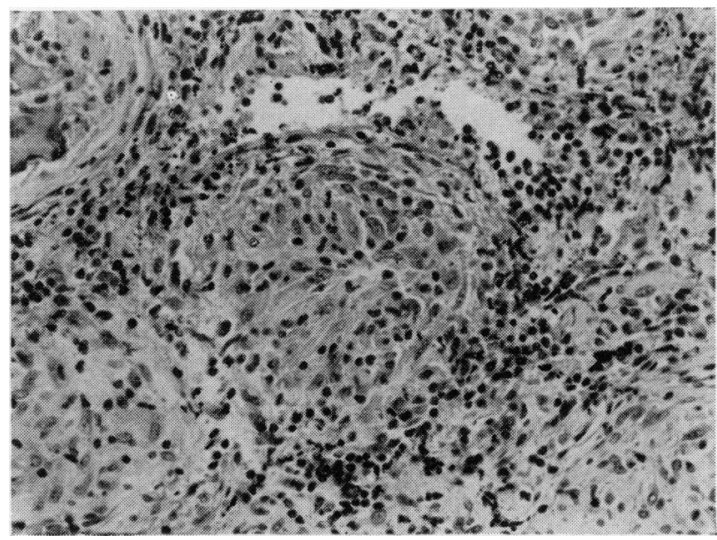

Fig. 1. Human sarcoid lymph node. Showing characteristic confluent epithelioid cell granulomata. (Stained $H \& E \times 160$.)

healthy subject. Homogenates were prepared in an identical manner from each fresh unfrozen tissue in $1 \%$ bovine albumin in saline, yielding approximately a $13.5 \%$ suspension. Each homogenate was injected $(0.03 \mathrm{ml})$ into the hind footpads of six normal and six immunologically deficient female CBA strain mice of 12 weeks of age; the latter prepared by adolescent thymectomy and whole body irradiation 
(900r). All homogenates were injected into guinea pigs and cultured on Lowenstein-Jensen medium to detect the presence of mycobacteria. The early and late changes were assessed histologically from full thickness biopsy of the footpads $(3 \mathrm{~mm}$ HayesMartin skin biopsy punch). The early biopsy specimens were taken at intervals between 11 and 95 days and the late biopsies between 176 and 237 days. Mice becoming sick were killed; their footpads and viscera were examined histologically. Kveim tests were made in the ear with a highly specific Type 1 test suspension, prepared according to the method of Chase \& Siltzbach (Chase, 1961) at intervals of between 42 and 217 days after footpad inoculation. These Kveim test sites were assessed macroscopically and microscopically following punch biopsy $(4 \mathrm{~mm})$ at intervals between 27 and 98 days later.

This study was of a preliminary nature and because we had no prior knowledge of the speed of development or nature of the cellular response in the footpads; usually only a proportion were sampled at any one time. At least one of the footpads of all the surviving mice receiving sarcoid homogenate and both footpads of all the mice receiving non-sarcoid homogenate were examined histologically. Because this method excluded the possibility of systematic sampling, the results are grouped according to type of homogenate and the period of time which had elapsed following inoculation.

\section{Microscopic definitions}

\section{1. 'Positive'}

The essential feature was the presence of one or more granulomata composed principally of epithelioid cells with occasional Langhans-type giant cells. The overall appearances closely resembled those seen in sections from spontaneous sarcoid lesions in man.

\section{2. 'Equivocal'}

(a) A diffuse arrangement of epithelioid cells with no true epithelioid cell granuloma.

(b) Focal collections of histiocytes (with less abundant cytoplasm and smaller round nuclei) with few or no epithelioid cells.

\section{3. 'Negative'}

(a) Non-specific inflammatory cells, mononuclear cells, lymphocytes, neutrophils, plasma cells, eosinophils.

(b) Foreign body reaction.

(c) Scar with fibroblasts or fibrocytes.

(d) Normal tissue.

\section{Results (normal mice)}

\section{Early histology}

The detailed results given in Table 1 show that changes typical of recent sarcoidosis were observed in six of the eleven footpads from twelve mice examined following inoculation with sarcoid homogenates (Fig. 2). In contrast, none of the six footpads from six mice given non-sarcoid homogenate showed these characteristics. However, there was a highly cellular inflammatory response (Fig. 3 ) which could be clearly differentiated.

\section{Late histology}

The detailed results given in Table 1 show that changes characteristic of late sarcoidosis were observed in eight of the twenty footpads examined following inoculation with sarcoid homogenates (Fig. 4). In contrast, none of the twelve footpads from each of the six mice given non-sarcoid homogenate showed these changes. Moreover, the inflammatory cellular response which was an early feature in these footpads was no longer apparent.

\section{Kveim tests}

The detailed results given in Table 3 show that microscopic changes characteristic of sarcoid granulomata were observed in three of nine mice tested in the group inoculated with sarcoid homogenates (Fig. 5). These positive Kveim tests developed only in the animals showing histological features of sarcoidosis in their footpads. In contrast, none of the Kveim tests given in each of the five mice receiving non-sarcoid homogenate showed these characteristics. In neither group were there macroscopic lesions at the test sites.

TABLE 1. Histological assessments of footpads in normal mice inoculated with sarcoid or non-sarcoid homogenate

\begin{tabular}{lcccccccc}
\hline \multirow{2}{*}{$\begin{array}{c}\text { Time of biopsy } \\
\text { following inoculation }\end{array}$} & Positive & Equivocal & Negative & & Positive & Equivocal & Negative \\
\cline { 2 - 3 } Early (28-46 days) & 6 & 0 & 5 & & 0 & 0 & 6 \\
Late (176-187 days) & 8 & 2 & 10 & & 0 & 0 & 12 \\
\hline
\end{tabular}

See Methods and Materials for definitions. 


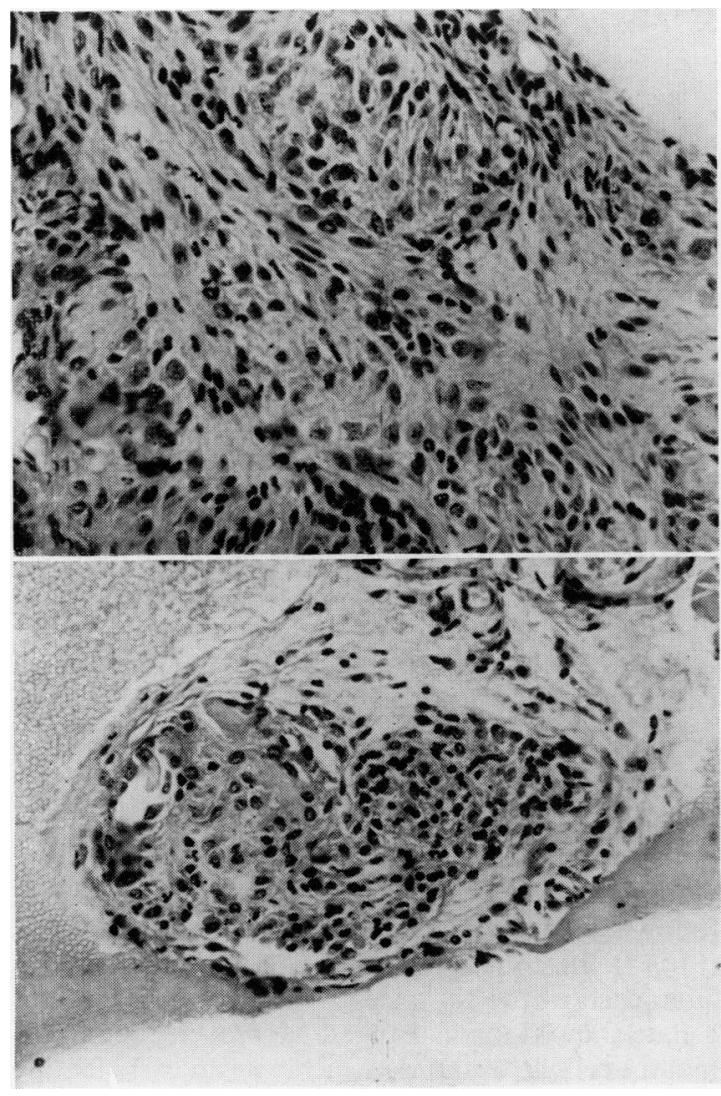

Fig. 2 (upper). Early histology of normal mouse footpad following inoculation of sarcoid homogenate. Showing characteristic arrangement of epithelioid cells within the confluent granulomata. (Stained H \& E $\times 215$.)

FIG. 3 (lower). Early histology of normal mouse footpad following inoculation of non-sarcoid homogenate. Showing highly cellular inflammatory response with small round cells predominant. (Stained H \& E $\times 160$.)

\section{Immunologically deficient mice}

The detailed results of the early and late histology and of Kveim tests are given in Tables 2 and 3, respectively. In general, all the findings are similar to those obtained in normal mice. Although, quantitatively, the proportion of mice showing characteristic sarcoid histology following inoculation of sarcoid homogenates was smaller than in normal mice, the only positive Kveim test was in one of the mice with sarcoid histology. However, in one footpad inoculated with non-sarcoid homogenate and examined early there were microscopic changes indistinguishable from sarcoidosis; these were not found later.

There were no macroscopic changes in the footpads of animals in any group. No mycobacteria

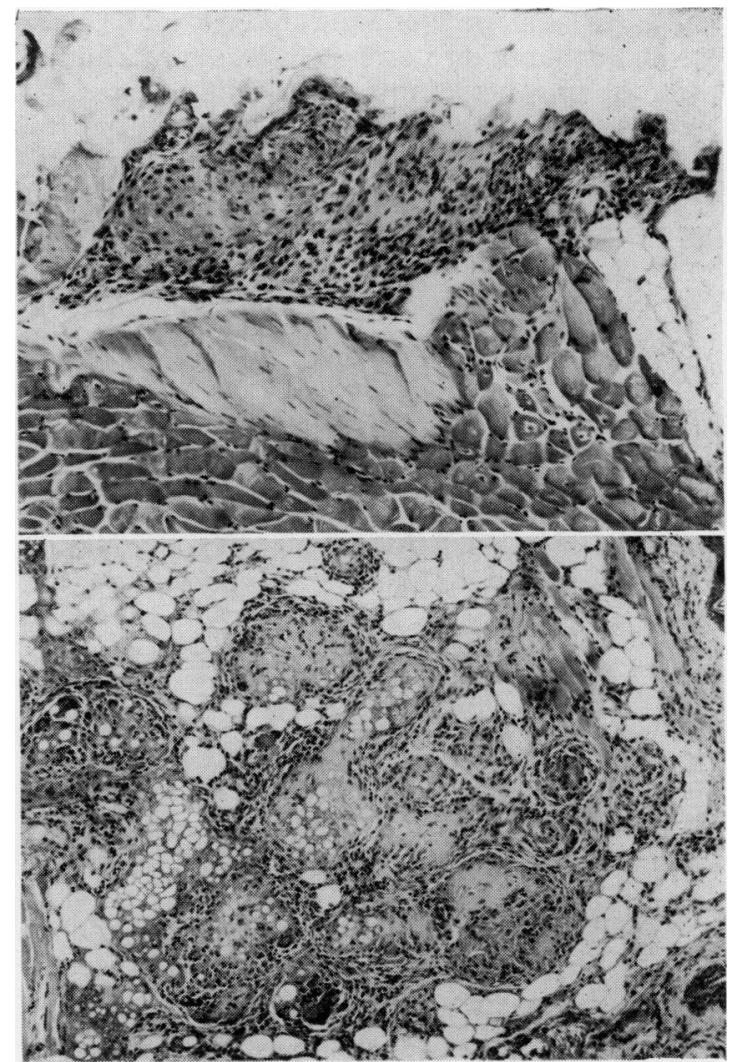

FIG. 4 (upper). Late histology of normal mouse footpad following inoculation of sarcoid homogenate. Showing characteristic hyaline fibrosis within confluent epithelioid cell granulomata. (Stained H \& E $\times$ 90.)

FIG. 5 (lower). Histology of Kveim test given in the ear of a normal mouse 161 days subsequent to footpad inoculation with sarcoid homogenate. Positive Kveim response with semi-confluent epithelioid cell granulomata with hyaline fibrosis, at 67 days. (Stained H \& E $\times 65$.)

were isolated in culture or in guinea pig from the lymph node homogenates.

\section{Discussion}

Although there have been several well-conducted attempts to isolate in culture a specific infectious agent from patients with sarcoidosis (Löfgren \& Lunkbäck, 1950, 1952; Mankiewicz, 1967; Sodja \& Votava, 1967; Hiomi Homma, Mikami \& Okano, 1967) none has yielded one. Similarly, attempts have been made to transmit sarcoidosis directly to animals by inoculation of sarcoid tissue. All these latter attempts were uncontrolled, usually based on single patients, and even positive claims have remained unsubstantiated (Ravaut, Valtis \& Nelis, 1929; Leigheb, 1933; Pautrier \& Glasser, 1936; Grillo, 
TABLE 2. Histological assessments of footpads in immunologically deficient mice inoculated with sarcoid or non-sarcoid homogenate

\begin{tabular}{|c|c|c|c|c|c|c|}
\hline \multirow{2}{*}{$\begin{array}{l}\text { Time of biopsy } \\
\text { following inoculation }\end{array}$} & \multicolumn{3}{|c|}{ Sarcoid } & \multicolumn{3}{|c|}{ Non-sarcoid } \\
\hline & Positive & Equivocal & Negative & Positive & Equivocal & Negative \\
\hline Early (11-95 days) & 6 & 4 & 14 & 1 & 3 & 2 \\
\hline Late (176-237 days) & 1 & 2 & 4 & 0 & 0 & 8 \\
\hline
\end{tabular}

See Methods and Materials for definitions.

TABLE 3. Histological assessments of Kveim tests in the ears of normal and immunologically deficient mice inoculated with sarcoid or non-sarcoid homogenate

\begin{tabular}{lccccccc}
\hline & \multicolumn{3}{c}{ Sarcoid } & & \multicolumn{3}{c}{ Non-sarcoid } \\
\cline { 2 - 3 } \cline { 7 - 8 } & Positive & Equivocal & Negative & & Positive & Equivocal & Negative \\
\hline $\begin{array}{l}\text { Normal mice } \\
\begin{array}{l}\text { Immunologically deficient } \\
\text { mice }\end{array}\end{array}$ & 3 & 2 & 4 & & 0 & 0 & 5 \\
\hline
\end{tabular}

See Methods and Materials for definitions.

1938, 1939; Santoianni, 1938; Amati, 1947, 1948; Croxatto, 1948; Rosenthal, 1949; Santoianni \& Ayala, 1949; Muratore \& Vulpis, 1952). Therefore, in part, our preliminary studies were designed to provide a more valid basis on which to attempt transmission of sarcoidosis to animals. In addition, we modelled our experiments on the mouse, using the footpad as the site for inoculation in both normal and immunologically deficient animals, because these methods have recently, and for the first time, provided a means of reproducing human leprosy experimentally (Shepard, 1960; Rees \& Weddell, 1968).

Our experimental design included normal and immunologically deficient mice of identical strain, sex and age. Moreover, homogenates from sarcoid and non-sarcoid lymph nodes were prepared identically, care being taken to avoid the possible inclusion of glass, cotton-wool or other foreign body material. The results have been assessed histologically according to the criteria used in man, and show several features of interest. The early histology of a substantial proportion of the footpads of mice inoculated with sarcoid homogenates showed characteristic granulomata which were clearly distinguished from the highly cellular inflammatory response seen after the same interval in the footpads of mice given non-sarcoid homogenate. Moreover, the sarcoid granulomata seen in the early histology subsequently showed changes characteristically associated with the pathology of sarcoidosis in man. The late histology of footpads inoculated with sarcoid homogenates showed the persistence of relatively fresh or progressively hyaline granulomata. In sharp con- trast, the highly cellular inflammatory lesions seen in the early histology of footpads inoculated with the non-sarcoid homogenate were no longer apparent in the same or contralateral footpad.

The specificity of the granulomata seen in mice given sarcoid homogenate was strongly supported by the responses elicited in the ears of these animals following injection of Kveim test material of proven specificity in man (Hurley \& Bartholomeusz, 1968). Thus, the positive Kveim tests observed were confined to those mice given sarcoid homogenate. Moreover, these positive Kveim tests were all associated with a sarcoid granuloma in the footpad.

It is of interest that all the characteristic histological features evolved over a period of 6-8 months and particularly relevant that the granulomatous lesions associated with human leprosy have recently been seen in the footpads of normal mice only after a prolonged interval of up to 2 years following inoculation (Rees et al., 1969).

Closely similar results were obtained in normal and immunologically deficient mice. However, early histology indistinguishable from that of human sarcoidosis was found in one of the immunologically deficient mice inoculated with non-sarcoid lymph node homogenate; this granulomatous response was no longer apparent in the late histology of the same or contralateral footpad and the Kveim test, given in the ear, was negative.

The results of this preliminary work are encouraging since it appears that an agent, admittedly unidentified, has in fact been transmitted to the mouse from human sarcoid tissues. Further work is, however, required to substantiate these findings 
by passage, by the demonstration of systemic lesions and to ascertain the characteristics of the agent, whether living or inert.

\section{Acknowledgments}

We thank Dr J. R. Mikhail, Mr J. F. Newcombe and Miss Mary Shephard for the lymph nodes. Dr T. H. Hurley kindly supplied the Kveim test material.

\section{References}

Amati, G. (1947) Experimental research in Besnier-BoeckSchaumann disease. Bollettino della Società italiana di biologia sperimentale, 23, 377-9.

AmATI, G. (1948) Biological and histological results with Ninni's intraganglionic test. Rivista dell Istituto sieroterapico italiano, 23, 229-46.

CARlens, E. (1959) Mediastinoscopy: A method for inspection and tissue biopsy in the superior mediastinum. Diseases of the Chest, 36, 343.

ChASE, M.W. (1961) The preparation and standardization of Kveim testing antigen. American Review of Respiratory Diseases, 84, (5 pt 2) 86-8.

Croxatro, O.C. (1948) Similarities between sarcoidosis and experimental tuberculoses in the hamster, Cricetus auratus. Archivos de la Sociedad argentina de anatomia normal y patológica, 10, 247-52.

Grillo, V. (1938) Contribution to Besnier-Boeck disease: sarcoid phase of infectious tuberculosis. Giornale italiano de dermatologia e sifilologia, 79, 547-69.

GrILlo, V. (1939) Production of histologic lesions of BesnierBoeck-Schaumann disease in lymph nodes of guinea pigs after intraperitoneal inoculation with broth from 'sarcoid' tissue. Archivio italiano di medicina sperimentale, 4, 515-22.

Hiomi Homma, A., Mikami, R. \& OKano, H. (1967) A study on the possible cause of sarcoidosis, La Sarcoidose, Rapports de la IV Conférence internationale, pp. 515-17. Masson et Cie, Paris.

Hurley, T.H. \& Bartholomeusz, C.L. (1968) Kveim test in sarcoidosis. Medical Journal of Australia, 2, 947-8.

LeIGHEB, V. (1933) Experimental research on histologic problems of tuberculid: first note. Giornale italiano de dermatologia e sifilologia, 74, 633-67.

LÖFGREN, S. \& LUNDBACK, H. (1950) Isolation of a virus from six cases of sarcoidosis. Acta medica Scandinavica, 138, 71-5.
LÖFGREN, S. \& LUNDBACK, H. (1952) Attempts at isolation of virus strains from cases of sarcoidosis and malignant lymphoma. II. Further isolation and control experiments. Acta medica Scandinavica, 143, 105-9.

MankIEwICZ, E. (1967) Le role des mycobacteries lysogenes dans l'etiologie de la sarcoidose, La Sarcoidose, Rapports de la IV Conférence internationale, pp. 487-95. Masson et Cie, Paris.

MURATORE, R. \& VulPIS, N. (1952) Modifications produced in guinea pigs by injection of fluids prepared from sarcoidosis materials, according to the technique of Lofgren \& Lundback. I. Anatomical and histological research. Bolletino della Società italiana di biologia sperimentale, 28, 169-72.

Pautrier, L.M. \& Glasser, R. (1936) Probable positive inoculation in a rabbit, at inoculation site of skin lesions from Besnier-Boeck-Schaumann disease. Bulletin de la Société française de dermatologie et de syphilographie, 43. 505-6.

Ravaut, P., Valtis, J. \& Nelis, P. (1929) Results of inoculation of sarcoid and papulonecrotic tuberculid in the guinea pig. Comptes rendus des séances de la Société de biologie et de ses filiales, 101, 444-5.

ReES, R.J.W. \& WedDell, A.G.M. (1968) Experimental models for studying leprosy. Annals of the New York Academy of Sciences, 154, 214-36.

Rees, R.J.W., Weddell, A.G.M., Palmer, E. \& Pearson, J.H.M. (1969) Human leprosy in normal mice. British Medical Journal, 3, 216.

Rosenthal, S.R. (1949) Pathological and experimental studies of Boeck's sarcoid. I. Report of a case with panarteritis, periarteritis, terminal hypertension and uremia, and the reproduction of sarcoid-like lesions in guinea pigs. American Review of Tuberculosis, 60, 236-48.

SantoianNi, G. (1938) Besnier-Boeck-Schaumann disease: experimental transmission in animals. Archivio italiano de dermatologia e sifilologia, 15, 78-90.

SantoianNi, G. \& Ayala, L. (1949) Experimental studies on the etiology of Besnier-Boeck-Schaumann disease. Results of the biologic test in animals. Annali italiani di dermatologia e sifolografia, 4, 9-16.

SHEPARD, C.C. (1960) The experimental disease that follows the injection of human leprosy bacilli into footpads of mice. Journal of Experimental Medicine, 112, 445-54.

SODJA, I. \& VotaVA, Vl. (1967) Isolation of myxovirus parainfluennzae in patients with sarcoidosis, La Sarcoidose, Rapports de la IV Conférence internationale, pp. 487-95. Masson et Cie, Paris. 